Article

\title{
Improving Hydrogen Embrittlement Resistance of Hot-Stamped 1500 MPa Steel Parts That Have Undergone a Q\&P Treatment by the Design of Retained Austenite and Martensite Matrix
}

\author{
Zhou Wang ${ }^{1,2}$ and Mingxin Huang ${ }^{1,2, *(1)}$ \\ 1 Department of Mechanical Engineering, The University of Hong Kong, Pokfulam Road, \\ Hong Kong 999077, China; zhou17@hku.hk \\ 2 Shenzhen Institute of Research and Innovation, The University of Hong Kong, Shenzhen 518000, China \\ * Correspondence: mxhuang@hku.hk; Tel.: +852-3917-7906; Fax: +852-2858-5415
}

Received: 18 October 2020; Accepted: 25 November 2020; Published: 26 November 2020

\begin{abstract}
Hydrogen embrittlement is one of the largest obstacles against the commercialisation of ultra-high strength quenching and partitioning $(\mathrm{Q} \& \mathrm{P})$ steels with ultimate tensile strength over $1500 \mathrm{MPa}$, including the hot stamped steel parts that have undergone a Q\&P treatment. In this work, the influence of partitioning temperature on hydrogen embrittlement of ultra-high strength Q\&P steels is studied by pre-charged tensile tests with both dog-bone and notched samples. It is found that hydrogen embrittlement resistance is enhanced by the higher partitioning temperature. Then, the hydrogen embrittlement mechanism is analysed in terms of hydrogen, retained austenite, and martensite matrix. Thermal desorption analysis (TDA) shows that the hydrogen trapping properties are similar in the Q\&P steels, which cannot explain the enhancement of hydrogen embrittlement resistance. On the contrary, it is found that the relatively low retained austenite stability after the higher temperature partitioning ensures more sufficient TRIP effect before hydrogen-induced fracture. Additionally, dislocation recovery and solute carbon depletion at the higher partitioning temperature can reduce the flow stress of the martensite matrix, improving its intrinsic toughness and reducing its hydrogen sensitivity, both of which result in the higher hydrogen embrittlement resistance.
\end{abstract}

Keywords: quenching and partitioning (Q\&P) steel; hydrogen embrittlement; retained austenite; martensite matrix; carbon partitioning

\section{Introduction}

As a third-generation advanced high strength steel (AHSS), quenching and partitioning (Q\&P) steels exhibit an excellent combination of strength and ductility for automotive body lightweighting [1-6]. The production of ultimate tensile strength and total elongation has reached over $30,000 \mathrm{MPa} \%$ in state-of-the-art Q\&P steels [7-9]. Up to now, some Q\&P steels have already been commercialized in the automotive industry, such as QP980, with ultimate tensile strength over $980 \mathrm{MPa}$ and total elongation over 20\% [1]. However, the ultra-high strength Q\&P steels, with ultimate tensile strength over $1500 \mathrm{MPa}$, still face several challenges before practical application [10-12]. Hydrogen embrittlement is one of the biggest challenges for ultra-high strength Q\&P steels. Hydrogen produced by galvanisation, painting, and corrosion can diffuse to regions of high residual or applied stress and degrade the fracture toughness, leading to pre-mature fracture of Q\&P steel components $[13,14]$. Ultra-high strength Q\&P steels are intrinsically more sensitive to hydrogen embrittlement, due to the higher residual stress and the larger fraction of martensite in the final microstructure [14-16]. Therefore, 
the hydrogen embrittlement risk and mechanism must be systematically evaluated and studied before the practical application of ultra-high strength Q\&P steels.

The study of hydrogen embrittlement of Q\&P steels has been focused on both the retained austenite and the martensite matrix, in some cases with ferrite and bainite $[14,15,17-20]$. The influence of retained austenite has two aspects. On the one hand, the metastable retained austenite transforms into martensite under external stress and strain, producing the transformation induced plasticity (TRIP) effect [4,7]. The TRIP effect guarantees the continuous work hardening of Q\&P steels during deformation, contributing to the strength-ductility balance $[4,21]$, which could also benefit the hydrogen embrittlement resistance. On the other hand, the deformation-induced martensite (DIM) due to the TRIP effect is mostly untempered high-carbon martensite $[9,12]$. The brittleness of DIM can promote the initiation of hydrogen-induced microcracks, degrading the hydrogen embrittlement resistance $[17,19,20]$. Hence, to restrict the propagation of these hydrogen-induced microcracks, the matrix should also be well-designed. Take QP980 as an example. The matrix of QP980 consists of ferrite, bainite, and martensite. Several methods have been proposed to improve its hydrogen embrittlement resistance by designing the matrix, including tailoring the ferrite distribution [14] and introducing $\varepsilon$-carbides in martensite [18]. On the contrary, in ultra-high strength Q\&P steels, hydrogen embrittlement has been rarely studied despite the increased risk. Additionally, differently from QP980, the microstructure of ultra-high strength Q\&P steels contains a larger fraction of retained austenite and almost full martensite matrix $[1,7,17]$. Thus, more studies should be conducted, and new methods should be developed to enhance the hydrogen embrittlement resistance of ultra-high strength Q\&P steels.

Recently, our research team has proposed a new heat treatment method to tailor simultaneously the retained austenite and the martensite matrix to enhance the strength-ductility-toughness combination of ultra-high strength Q\&P steels [12]. Research shows that the higher partitioning temperature can enhance the dislocation recovery and the solute carbon depletion to reduce the flow stress and increase the intrinsic toughness of the martensite matrix while maintaining enough retained austenite with the TRIP effect. This new method could potentially enhance the hydrogen embrittlement resistance, especially for the hot stamped steel parts that have undergone a Q\&P treatment recently developed $[22,23]$. Therefore, in this work, hydrogen embrittlement is studied for two ultra-high strength Q\&P steels with different partitioning temperatures. The hydrogen embrittlement is analysed in terms of hydrogen content, retained austenite, and martensite matrix. It is found that by the design of retained austenite and martensite matrix, the hydrogen embrittlement resistance can be improved, which could promote the future commercialisation of ultra-high strength Q\&P steels.

\section{Materials and Methods}

The as-rolled steels sheets are received from the industry, with chemical compositions summarised in Table 1. The Q\&P heat treatment is conducted in a L78 QD dilatometer (Linseis Messgeraete $\mathrm{GmbH}$, Selb, Germany). The heat treatment procedures are summarised in Figure 1a. The heating austenitisation and cooling conditions are selected according to our previous study, which suppresses the formation of ferrite or bainite and results in desirable fraction of retained austenite [7,12]. In this work, two partitioning temperatures are selected, i.e., $350^{\circ} \mathrm{C}$ and $450{ }^{\circ} \mathrm{C}$, referred hereafter as $1500 \mathrm{LT}$ and $1500 \mathrm{HT}$, respectively. The dilatometer allows for the accurate heat treatment control, which is necessary in this work.

Table 1. Chemical compositions (wt. \%) of as-received steel sheets.

\begin{tabular}{ccccccccc}
\hline Element & $\mathbf{C}$ & $\mathbf{S i}$ & $\mathbf{M n}$ & $\mathbf{P}$ & $\mathbf{S}$ & Al & $\mathbf{N}$ & Fe + Others \\
\hline $\mathrm{wt}^{2} \%$ & 0.3 & 1.57 & 2.94 & 0.0036 & 0.0039 & 0.022 & $\leq 0.004$ & bal. \\
\hline
\end{tabular}


(a)

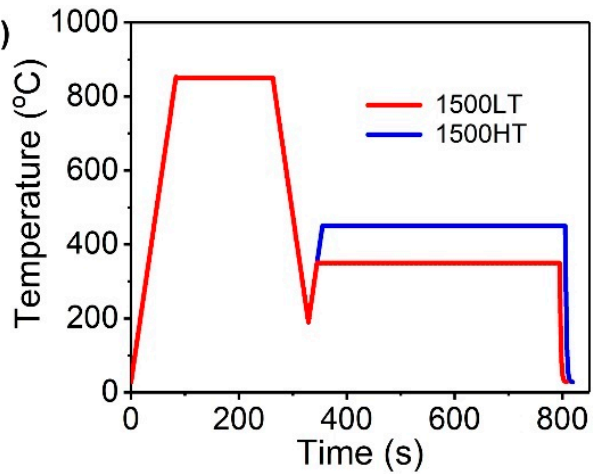

(b)

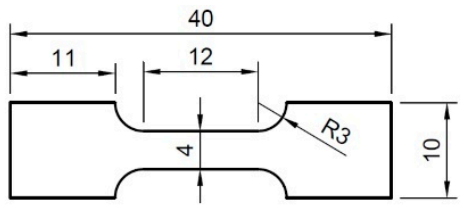

(c)

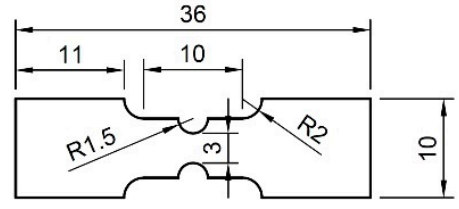

Figure 1. Heat treatment procedures and tensile samples for the two Q\&P steels: (a) Heat treatment procedures; (b) Dog-bone samples; (c) Notched samples. The dimensions in (b,c) are in the unit of $\mathrm{mm}$.

The geometry of tensile samples is described in Figure 1b,c. Pre-charged tensile tests are conducted on a universal testing machine with a $10-\mathrm{mm}$-guage extensometer. The pre-charging is conducted in a solution of $3 \mathrm{wt} \% \mathrm{NaCl}$ and $3 \mathrm{~g} \mathrm{l}^{-1} \mathrm{NH}_{4} \mathrm{SCN}$ in deionised water with a charging current density of $0.5 \mathrm{~mA} \mathrm{~cm}^{-2}$. Dog-bone samples are pre-charged for $5 \mathrm{~h}$ and deformed at a strain rate around $10^{-2}$, while notched samples are pre-charged for $2 \mathrm{~h}$ and deformed at a crosshead rate of $10^{-3}$. The reason that slow strain rate tests are not adopted in this work is to suppress the influence of inclusions, which is difficult to control during the fabrication of medium Mn steels. This will be discussed in another paper from our research group, publishing soon. Before hydrogen pre-charging, all samples are grinded by sandpapers, up to 1200 grit. To evaluate quantitatively the hydrogen embrittlement resistance, elongation loss is measured for dog-bone samples as in [14], while von Mises stress loss is measured for notched samples, calculated by finite element method (FEM) using Abaqus. In the FEM modelling, the steels are assumed to be homogeneous and have an isotropic hardening behaviour. The true stress-strain data from uniaxial tensile tests without hydrogen charging is used as input for the modelling. The C3D8R element, an 8-node linear brick with reduced integration, is used for meshing in Abaqus, with a mesh size around $0.25 \mathrm{~mm}$ at the notch regions.

To estimate the hydrogen concentration in pre-charged samples, thermal desorption analysis (TDA) is performed separately by samples with a dimension around $4 \mathrm{~mm} \times 10 \mathrm{~mm} \times 1.2 \mathrm{~mm}$. The TDA is performed using a Bruker G4 Phoenix diffusible hydrogen analyser (Bruker, Billerica, MA, USA). The heating rate is $0.3^{\circ} \mathrm{C} \mathrm{s}^{-1}$ and the carrier gas is pure nitrogen. The TDA data are fitted by Gaussian function using the software package Fityk [24].

Specimens for scanning electron microscopy (SEM), electron backscatter diffraction (EBSD), X-ray diffraction (XRD), and neutron diffraction (ND) are grinded, then electropolished in a mixed solution of glacial acetic acid and perchloric acid. The SEM was conducted on a Sigma 300 (Zeiss, Jena, Germany) with a Symmetry EBSD detector (Oxford Instruments, Oxfordshire, UK). For transmission electron microscopy (TEM), specimens are twinjet electropolished then ion-milled to remove contaminations to characterize fine cementite precipitates. The TEM is performed on a TECNAI G2 (FEI, Hillsboro, OR, USA) operated at $200 \mathrm{kV}$. The ND experiments are conducted by General Purpose Powder Diffractometer (GPPD) at China Spallation Neutron Source (CSNS), Dongguan, China. The volume fraction and lattice parameter of retained austenite and martensite matrix is obtained by Rietveld refinement using the GSAS software package [25]. Texture is not considered during the Rietveld refinement. In addition, for martensite matrix, the sub-grain size, dislocation density, dislocation arrangement, and dislocation character are also obtained from the ND experiments by the Modified Warren-Averbach (MWA) Method combined with the Modified Williamson-Hall (MWH) Method [26-29]. The diffraction profiles of $(110) \alpha,(200) \alpha,(211) \alpha,(220) \alpha,(310) \alpha$, and (400) $\alpha$ are used for the MWA and the MWH methods. Standard strain-free Si powders are used to eliminate instrumental errors. Finally, the XRD is performed on a Smartlab diffractometer (Rigaku, Tokyo, Japan) with Co-K $\alpha$ radiation at room temperature. The volume fraction of retained austenite is calculated by XRD according to the ASTM 
E975 standard, with integrated intensities of (110) $\alpha,(200) \alpha$, and (211) $\alpha$ and (200) $\gamma,(220) \gamma$, and (311) $\gamma$ reflections [30].

\section{Results}

The microstructure of the two Q\&P steels are shown in Figures 2 and 3. Both Q\&P steels show a microstructure comprised of lath martensite matrix and retained austenite. The size of martensite packets and blocks are similar in the two Q\&P steels, consistent with the same austenisation and quenching condition. However, the substructures of the martensite laths are different. As shown in Figure 2a,b, the martensite laths of the 1500LT sample contain a high density of needle-like transition carbides, while in the $1500 \mathrm{HT}$ samples, spherical carbides are observed to precipitate along various martensite grain boundaries and austenite/martensite phase boundaries. Figure $2 \mathrm{c}$ shows more clearly the morphology of the spherical carbides, the diameter of which is about tens of nanometres. The apparently continuous morphology is due to the overlapping of several separate carbides. In addition, the diffraction pattern in Figure $2 \mathrm{~d}$ justifies that these spherical carbides are cementite [31].
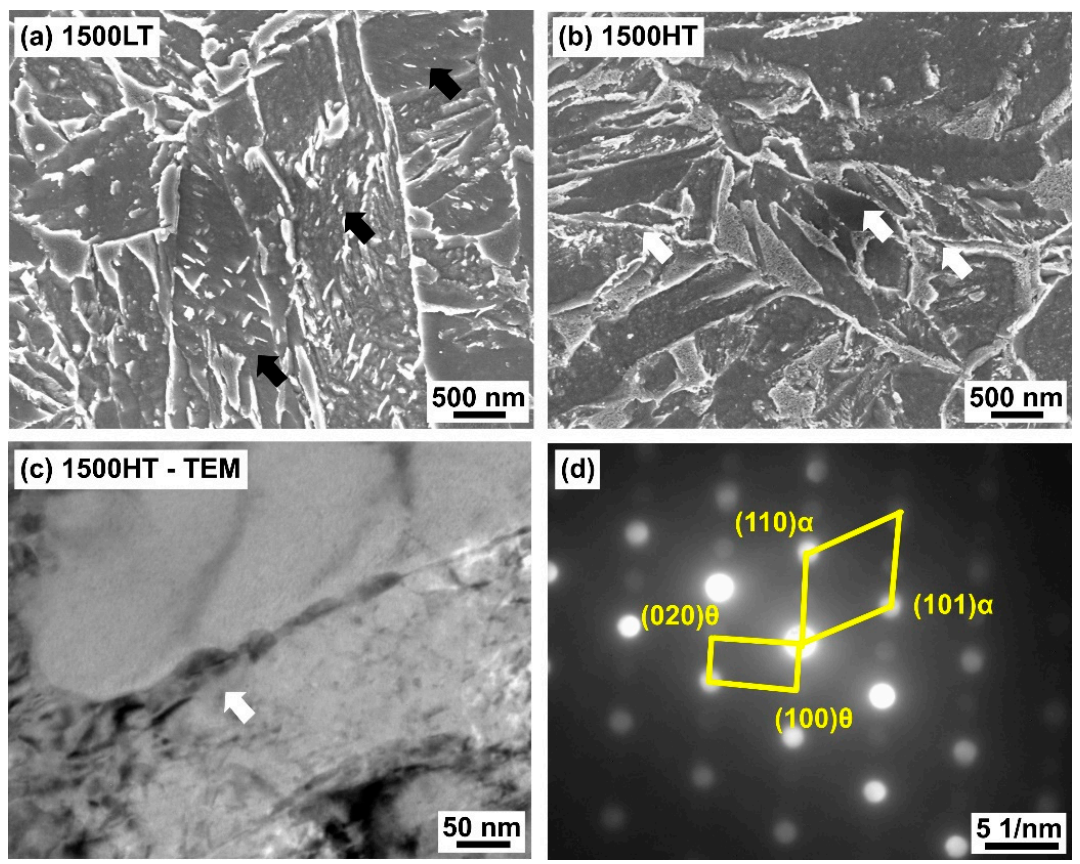

Figure 2. Microstructure of the two Q\&P steels: (a) 1500LT; (b-d) 1500HT. (a,b) are scanning electron microscopy (SEM) images. The arrows in (a) point to the transition carbides, and the arrows in (b) point to the cementite. (c) is a transmission electron microscopy (TEM) image. (d) is the diffraction pattern of the region marked by the arrow in (c).

In Figure 3, the electron backscattered diffraction (EBSD) images show the morphology and distribution of retained austenite. Both the size and the fraction of retained austenite are similar in $1500 \mathrm{HT}$ and 1500LT, which corresponds to the same quenching rate and temperature [7]. Considering that the EBSD results may be influenced by factors such as the surface effects, quantitative characterisation is conducted further by neutron diffraction (ND) [32-34]. ND obtains the information of the entire bulk samples. The volume fractions of retained austenite, measured by ND, are $17.2 \%$ and $17.8 \%$ in 1500LT and 1500HT, respectively, consistent with the similar fraction under EBSD. Therefore, the partitioning treatments of both steels work well to stabilise retained austenite at room temperature and avoid the decomposition of retained austenite into bainite or cementite. In terms of reverted austenite, localised high carbon content is required to reach the critical driving force at relatively low temperatures as in this work, i.e., $400{ }^{\circ} \mathrm{C}$ and $450{ }^{\circ} \mathrm{C}$ [35]. In $1500 \mathrm{HT}$, the formation 
of cementite at grain and phase boundaries consumes the carbon concentration, probably making reverted austenite insignificant.
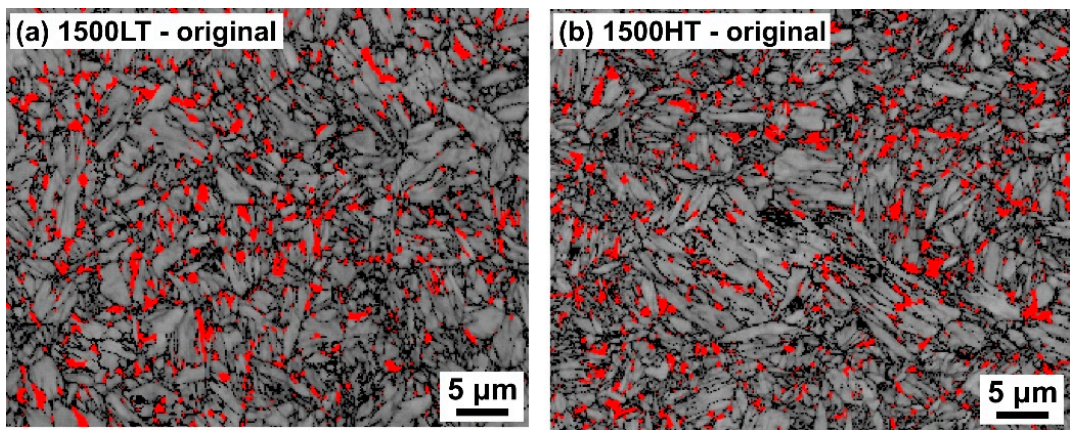

Figure 3. Microstructure of the two Q\&P steels by electron backscattered diffraction (EBSD): (a) 1500LT; (b) $1500 \mathrm{HT}$. The EBSD images are band contrast maps overlapped by phase maps, where the red phase is retained austenite. The black refers to the zero index areas.

The mechanical properties of the Q\&P steels are given in Figure 4. The ultimate tensile strengths of 1500LT and 1500HT are both close to $1500 \mathrm{MPa}$ before hydrogen charging, as shown by the dotted lines in Figure 4a. However, the yield strength and the uniform elongation are all better in 1500LT samples. The higher yield strength can be due to the lower partitioning temperature, which results in the higher yield stress of the martensite matrix. The higher uniform elongation in 1500LT can be explained by the better retained austenite stability [1,7], which will be shown later in the Discussion section. For energy absorption parts on automotive bodies, the design of which is based on the ultimate tensile strength [36], 1500LT and 1500HT show similar lightweighting capabilities.

Despite the excellent strength-ductility combination, both steels suffer from significant hydrogen degradation after pre-charging. Evaluated by elongation loss, $1500 \mathrm{HT}$ samples show smaller ductility loss, probably corresponding to the better hydrogen embrittlement resistance. However, the fracture strength of $1500 \mathrm{HT}$ after hydrogen pre-charging is lower than 1500LT. In literature, the elongation loss is more commonly used to evaluate hydrogen embrittlement of dog-bone samples of ductile steels, rather than strength loss [14,18,37-39]. In addition to dog-bone samples, hydrogen embrittlement of notched samples is studied. The FEM modelling is conducted to measure the maximum von Mises stress around the notch at the fracture point. In Figure $4 \mathrm{~b}$, it can be observed that the von Mises stress loss of $1500 \mathrm{HT}$ is lower than 1500LT after hydrogen pre-charging. Therefore, the mechanical tests demonstrate that the $1500 \mathrm{HT}$ shows better hydrogen embrittlement resistance than 1500LT.
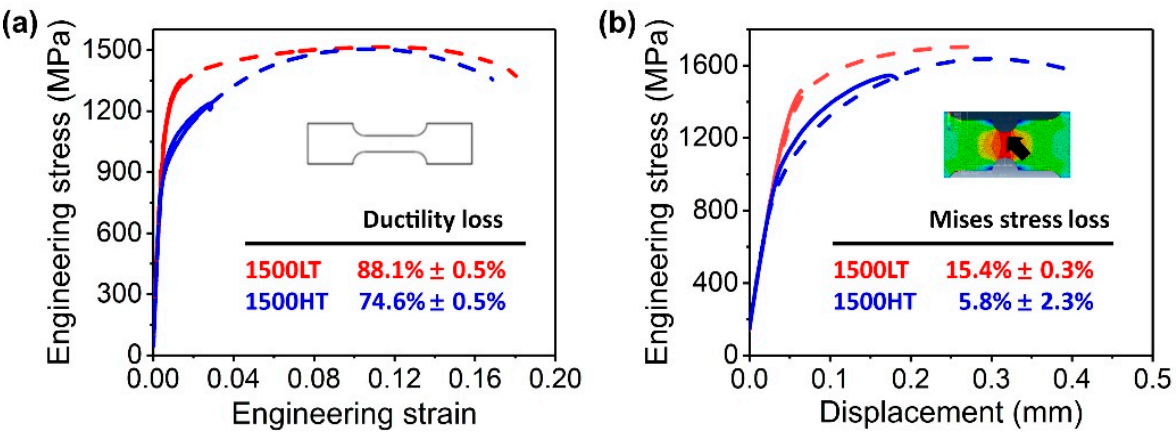

Figure 4. Mechanical properties of the two Q\&P steels, evaluated with (a) dog-bone samples, (b) notched samples. Solid and dotted lines are tensile curves with and without hydrogen pre-charging, respectively. The engineering stress in (b) is calculated by dividing the loading force by the smallest area section on the original tensile samples. The inset tables show quantitatively the hydrogen degradation of the mechanical properties. 
Figure 5 shows the fractography of hydrogen pre-charged samples. In Figure 5a,b, the fisheye morphology is observed in hydrogen pre-charged dog-bone samples of both 1500LT and 1500HT [40,41]. In both Q\&P steels, hydrogen-induced fracture initiates at an inclusion, then propagates around the inclusion, leading to the fisheye morphology. The fracture morphologies around the inclusion are mixtures of intergranular fracture and transgranular fracture in both steels, with a higher fraction of intergranular fraction in 1500LT, as shown in Figure 5a,b. The higher fraction of intergranular fraction corresponds to the lower hydrogen embrittlement resistance in 1500LT [14]. However, due to the influence of inclusions, the dog-bone samples of both steels suffer from severe hydrogen embrittlement, and $1500 \mathrm{HT}$ shows only a slight improvement of hydrogen embrittlement resistance according to the elongation loss. In ultra-high strength Q\&P steels, the medium Mn content (around $3 \mathrm{wt} \%$ ) may introduce more inclusions during smelting than usual. Thus, the control of inclusions is important to enhance the hydrogen embrittlement resistance, which could be a future focus. The present work will focus more on the multiphase microstructure of retained austenite and martensite matrix.

Compared with the dog-bone samples, the hydrogen assisted fracture begins at the notch tip due to the stress and strain localisation in notched samples. No fisheye morphology is observed. The influence of the inclusion is suppressed, which accounts for the more obvious hydrogen embrittlement difference between 1500LT and 1500HT. The typical fracture morphologies of the notched samples are shown in Figure 5c,d. In 1500LT, the intergranular fracture dominates, while in 1500HT, the transgranular fracture dominates. The severer intergranular fracture in 1500LT accounts for the larger von Mises stress loss during hydrogen pre-charged tests. Therefore, the fracture morphology is consistent with the mechanical properties, demonstrating that 1500HT has better hydrogen resistance than 1500LT.
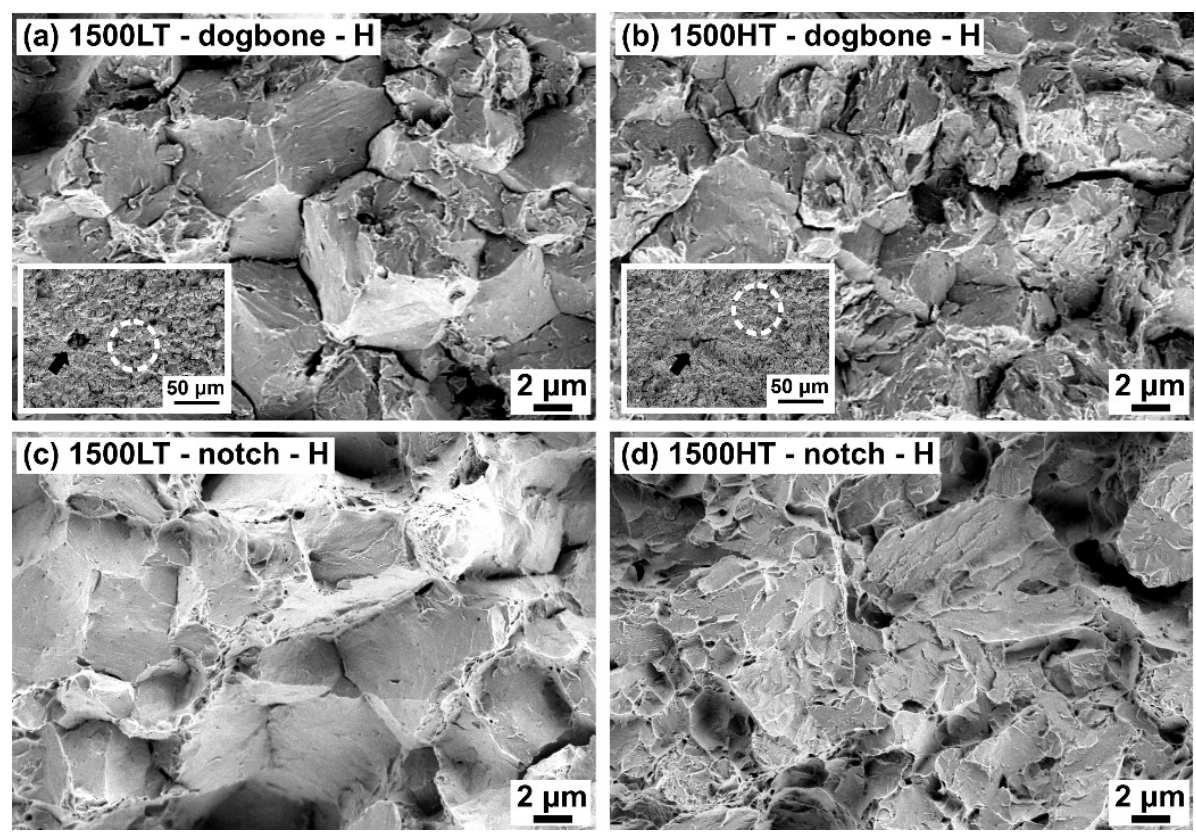

Figure 5. Fractography of hydrogen pre-charged samples: (a,c) 1500LT; (b,d) 1500HT. (a,b) are for dog-bone samples. (c,d) are for notched samples. The inset SEM images in $(\mathbf{a}, \mathbf{b})$ are the low magnification images that show the fisheye morphology. The arrows point to the inclusions. The circles mark the regions for high magnification images.

According to the literature, despite the TRIP effect, metastable retained austenite will transform into brittle deformation-induced martensite, which is the main cause of intergranular fracture of Q\&P steels without hydrogen $[9,12,42]$. The higher partitioning temperature can reduce the flow stress of the martensite matrix, which promotes the dislocation movement in front of the microcracks initiated at metastable retained austenite, thus reducing the risk of intergranular fracture [12]. In this work, after hydrogen charging, the higher partitioning temperature is observed to suppress the hydrogen-assisted 
intergranular fracture too. This might also be related to the toughening of the martensite matrix. Meanwhile, hydrogen can segregate to grain boundaries and exacerbate the risk of the intergranular fracture, known as the hydrogen enhanced decohesion (HEDE) mechanism. The influence of hydrogen, retained austenite, and martensite matrix will be discussed below in more detail.

\section{Discussion}

\subsection{Hydrogen}

To discuss the hydrogen embrittlement resistance of 1500LT and 1500HT, the influence of hydrogen trapping properties should be discussed first. The hydrogen trapping properties, including hydrogen diffusivity and solubility, can influence the amount of pre-charging hydrogen and the hydrogen distribution during tensile tests, thus playing an important role in the hydrogen embrittlement resistance [43-45]. Figure 6 demonstrates the trapping properties of 1500LT and 1500HT by the TDA curves and the diffusible hydrogen content obtained from TDA. As shown in Figure 6, both the diffusible hydrogen content and the shape of the TDA curves are similar in 1500LT and 1500HT, indicating the similar hydrogen trapping properties.

The similar trapping properties can be explained in terms of the carbides, martensite matrix, and the retained austenite [43-45]. According to recent research on multiphase steels, the carbides, formed during quenching or partitioning, may have negligible influences on the hydrogen trapping, due to the relative weak binding energy and the high density of other hydrogen traps [43]. For the martensite matrix, both grain boundary area and dislocation density need to be considered. The same austenitisation and quenching condition in this work lead to the very similar prior austenite grain boundary, martensite packet boundaries, and block boundaries. On the other hand, due to the higher partitioning temperature, the lath martensite boundary areas and the dislocation density might be lower in $1500 \mathrm{HT}$, which reduces hydrogen traps and in turn increases hydrogen diffusivity and decrease hydrogen solubility [4]. However, research by Turk et al. also shows that the influence of about $3.5 \mathrm{vol} \%$ retained austenite is already much larger than the influence of martensite matrix in quenched and tempered martensitic steels [43]. Considering the retained austenite fraction of about $17 \mathrm{vol} \%$ in this work, the retained austenite is expected to play the major role in hydrogen trapping. Since the retained austenite morphology and fraction are similar in the two steels, the trapping properties should also be similar, consistent with the TDA results in Figure 6. Therefore, the similar hydrogen trapping properties cannot explain the improvement of hydrogen embrittlement resistance.

(a)

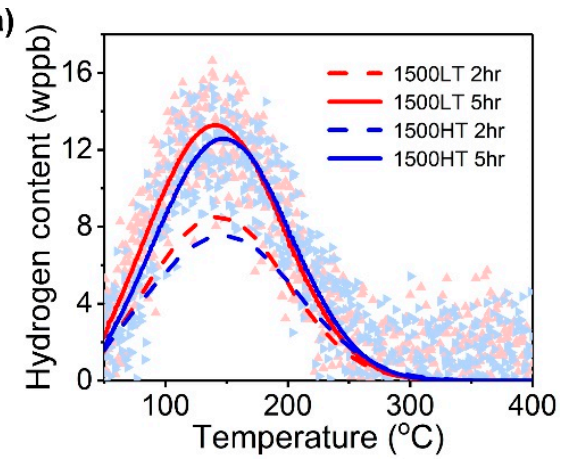

(b)

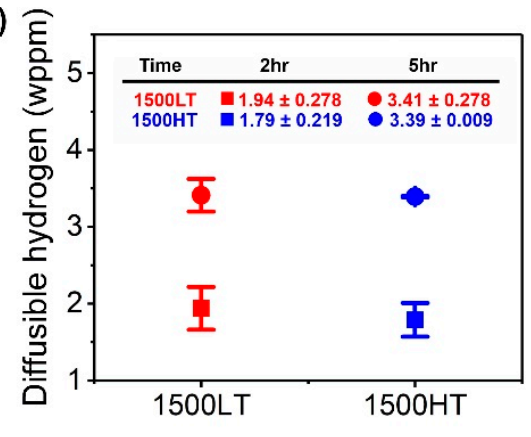

Figure 6. Thermal desorption analysis (TDA) of the two Q\&P steels: (a) TDA curves; (b) Diffusible hydrogen content obtained from TDA. The semi-transparent dots in (a) are original data for $5 \mathrm{~h}$ pre-charged samples. The solid and dotted lines are for $2 \mathrm{~h}$ and $5 \mathrm{~h}$ pre-charged samples, respectively, fitted by Gaussian function. Note that the dilatometric Q\&P process limits the size of the TDA samples, described in Section 2, which accounts for the scattering of raw data. The error bars in (b) are standard deviations from at least two data points. The inset table shows the quantitative results of hydrogen content in the unit of wppm. 


\subsection{Retained Austenite}

Retained austenite is important to both the strength-ductility balance and the hydrogen embrittlement resistance. Figure 7 shows the evolution of retained austenite fraction during deformation without hydrogen pre-charging. It is observed that the retained austenite transforms continuously in 1500LT, which is desirable for the optimisation of the strength-ductility balance, as shown in Figure 4. In comparison, the retained austenite in $1500 \mathrm{HT}$ is much less stable, with over $50 \%$ transformed at the engineering strain of $2.5 \%$ and almost $100 \%$ transformed before necking. The lower retained austenite stability can be caused by the lower austenite carbon content and the softer martensite matrix in $1500 \mathrm{HT}$. The austenite carbon content can be obtained from the lattice parameter by using an empirical equation (Table 2) [7]. However, due to the similar original retained austenite fraction, the strength-ductility combination of $1500 \mathrm{HT}$ is still maintained at an excellent level similar to 1500LT, as in Figure 4.

Here, the mild hydrogen pre-charging condition is assumed not to influence the mechanical stability of retained austenite. Thus, during the deformation of pre-charged samples, the retained austenite in 1500LT is still much more stable than that in $1500 \mathrm{HT}$. However, due to the premature fracture induced by hydrogen embrittlement, the continuous TRIP effect can no longer work effectively in 1500LT. Take dog-bone samples as an example. 1500LT samples fracture at an engineering strain around $1.4 \%$, consuming only $9.3 \%$ of the total austenite; in contrast, $1500 \mathrm{HT}$ samples fracture at an engineering strain around $2.8 \%$, consuming $63.1 \%$ of the total austenite. The TRIP effect can absorb extra energy during the fracture $[12,46,47]$ and reduce the hydrogen degradation in $1500 \mathrm{HT}$.

Table 2. Microstructure parameters in the two Q\&P steels, 1500LT and 1500HT. The austenite carbon concentration is calculated from the empirical equation, where Mn concentration is approximately taken to be $2.94 \mathrm{wt} \%$. The volume fracture and lattice parameter are obtained from the Rietveld refinement of neutron diffraction data. The sub-grain size, dislocation density, $\mathrm{q}$ value, and $\mathrm{M}$ value are obtained from the Modified Warren-Averbach (MWA) Method combined with the Modified Williamson-Hall (MWH) Method.

\begin{tabular}{|c|c|c|c|c|c|}
\hline \multirow[b]{2}{*}{ Materials } & \multicolumn{5}{|c|}{ Retained Austenite } \\
\hline & $\begin{array}{c}\text { Volume } \\
\text { fraction (\%) }\end{array}$ & $\begin{array}{c}\text { Lattice } \\
\text { parameter }(\AA)\end{array}$ & \multicolumn{3}{|c|}{$\begin{array}{l}\text { Carbon concentration }(\mathrm{wt} \%) \text { calculated from the } \\
\text { empirical equation: } a_{\gamma}=3.556+0.0453 x_{\mathrm{C}}+0.00095 x_{\mathrm{Mn}}\end{array}$} \\
\hline 1500LT & 17.2 & 3.59884 & & 0.884 & \\
\hline \multirow[t]{2}{*}{$1500 \mathrm{HT}$} & 17.8 & 3.59646 & & 0.831 & \\
\hline & \multicolumn{5}{|c|}{ Martensite Matrix } \\
\hline Materials & $\begin{array}{l}\text { Volume } \\
\text { fracture (\%) }\end{array}$ & $\begin{array}{c}\text { Lattice } \\
\text { parameter }(\AA)\end{array}$ & $\begin{array}{l}\text { Dislocation density } \\
\qquad\left(10^{16} \mathrm{~m}^{2}\right)\end{array}$ & q value & $\mathrm{M}$ value \\
\hline 1500LT & 82.8 & 2.86400 & 1.44 & 1.84 & 6.08 \\
\hline $1500 \mathrm{HT}$ & 82.2 & 2.86298 & 0.801 & 1.84 & 5.52 \\
\hline
\end{tabular}

On the other hand, it is pointed out that the TRIP effect can introduce deformation-induced martensite (DIM), which may be very susceptible to hydrogen embrittlement due to the high tetragonality and the instant hydrogen oversaturation. The DIM can also lead to stress concentration and triaxiality in the martensite matrix, promoting the propagation of hydrogen-induced cracks. According to the literature, the brittleness of DIM plays the leading role in the hydrogen embrittlement of the Q\&P steels, instead of the beneficial TRIP effect [17-19,48]. In this work, more DIM is produced in $1500 \mathrm{HT}$ before the hydrogen-induced fracture, which, however, does not degrade the hydrogen embrittlement resistance as much as in 1500LT. To explain this, the influence of the martensite matrix is discussed below. 


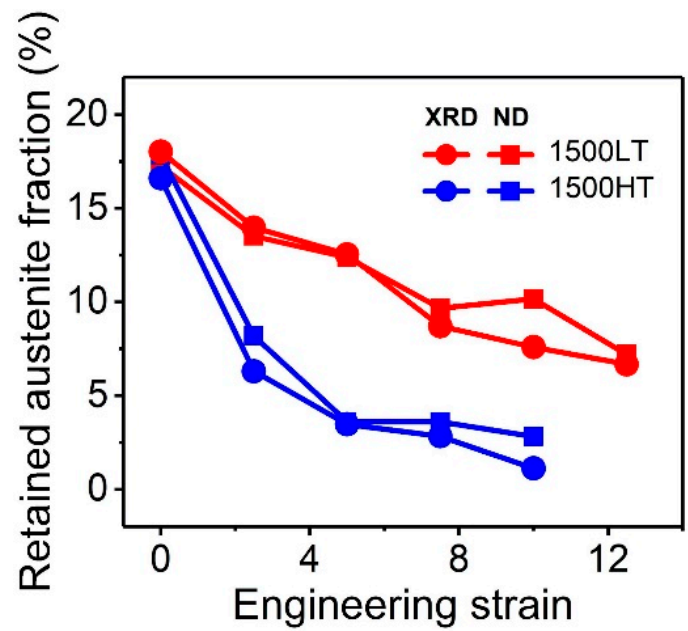

Figure 7. Evolution of retained austenite fraction during tensile deformation of dog-bone samples before the necking point.

\subsection{Martensite Matrix}

Once the hydrogen-induced microcracks are initiated at the DIM, the martensite matrix plays an important role in the crack propagation process [12] and thus the hydrogen embrittlement resistance. According to Figure 2, the sizes of martensite packets and blocks are similar in the two Q\&P steels due to the same austenitisation and quenching condition, while the martensite lath substructures are different due to the different partitioning temperatures [49]. Here, the martensite lath substructure is analysed in more details by neutron diffraction, as shown in Table 2. Firstly, the dislocation recovery is analysed. It is observed that the dislocation density decreases, the sub-grain size increases, and the dislocation arrangement evolves into non-uniform distribution (indicated by the M value) in 1500HT [26,50]. Secondly, the solute carbon concentration is qualitatively characterised by the lattice parameter of martensite in Table 2. Due to the low solute carbon concentration in martensite and other influential factors such as internal stress and carbon segregation, the lattice parameter of martensite cannot be easily used to obtain quantitative carbon concentration [49,51]. However, as the lattice parameter decreases at the higher partitioning temperature, it can be inferred that the solute carbon concentration also decreases [52]. The reduction of solute carbon concentration is mainly due to the formation of cementite in 1500HT.

Now it is evident that the martensite matrix of $1500 \mathrm{HT}$ is more sufficiently tempered due to the higher partitioning temperature. The benefits of the more sufficiently tempered martensite can be explained from two aspects. Firstly, the flow stress of the martensite matrix in 1500HT is lower due to the higher partitioning temperature [49], which restricts the propagation of microcracks initiated by hydrogen at the DIM. Instead of intergranular fracture, dislocation movement takes place at the microcrack tips in $1500 \mathrm{HT}$, restricting the crack propagation [12]. Secondly, the sufficiently tempered martensite is less sensitive to hydrogen degradation. The microcracks initiated at the DIM cause stress concentration and triaxiality in the martensite matrix, which attracts hydrogen and reduces the fracture resistance of the matrix. Upon the fracture resistance of the matrix is reduced to a critical level, the hydrogen-induced microcracks can propagate and lead to the hydrogen embrittlement. In 1500HT, the martensite lattice distortion is smaller due to the lower solute carbon content, and the stress concentration is also less severe due to the accommodation of dislocation movement. Both contribute to the smaller hydrogen degradation of the fracture resistance of the martensite matrix [14,53].

Meanwhile, it is also pointed out that the formation of cementite along martensite packet and block boundaries does not reduce the ductility and the hydrogen embrittlement resistance in this work. The reason might be that the size of the cementite particles is very fine with a diameter around tens of nanometres, probably due to the consumption of solute carbon by the retained austenite $[12,43]$. 
The tempered martensite embrittlement (TME) reported in literature is usually associated with large carbides with a length around hundreds of nanometres [54].

Figure 8 shows the schematism of the improvement of hydrogen embrittlement resistance in $1500 \mathrm{HT}$. The hydrogen embrittlement resistance is related to both the original fracture resistance without hydrogen and the degree of hydrogen degradation. On the one hand, 1500HT has better fracture resistance due to the lower flow stress of the sufficiently tempered martensite, indicated by the higher original position on the dotted lines. On the other hand, $1500 \mathrm{HT}$ also shows smaller hydrogen degradation than 1500LT, due to the larger amount of the TRIP effect and the lower hydrogen sensitivity of the martensite matrix itself, indicated by the shorter arrow of hydrogen degradation. Future development of hydrogen-embrittlement-resistant Q\&P steels can be designed from these two aspects.

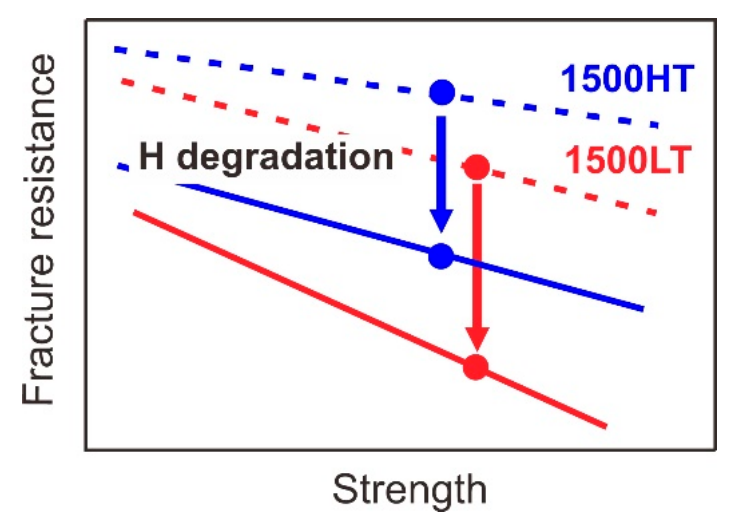

Figure 8. Schematism to explain the improvement of hydrogen embrittlement resistance of $1500 \mathrm{HT}$. The dotted lines demonstrate the fracture resistance-strength curves before hydrogen pre-charging, while the solid lines demonstrate the fracture resistance-strength curves after hydrogen pre-charging.

It is pointed out that the present work is limited to the Q\&P steel without pre-deformation. Thus, for practical applications, the proposed higher partitioning temperature is expected to work effectively in the hot stamped components that have undergone a Q\&P treatment. However, Q\&P steels might also be used for cold-formed components, where severe plastic deformation will be produced. After the plastic deformation, most of retained austenite will transform into martensite in 1500HT. Thus, the benefit of the TRIP effect against hydrogen embrittlement no longer works in 1500HT. Meanwhile, the yield stress of martensite matrix in $1500 \mathrm{HT}$ may also increase after plastic deformation, degrading the hydrogen embrittlement resistance. The recent publication by the authors show that after $5 \%$ plastic deformation, the fracture resistance of $1500 \mathrm{HT}$ will be reduced [12]. However, the fracture resistance of $1500 \mathrm{HT}$ is still much better than the counterpart undergone a lower partitioning temperature [12]. Accordingly, the benefit of higher intrinsic fracture resistance in 1500HT may still work for the better hydrogen embrittlement resistance after cold forming, compared with the 1500LT. Therefore, the higher partitioning temperature could still be a potential way to improve the hydrogen embrittlement resistance of cold formed Q\&P steel components, although more future work must be conducted to obtain a solid conclusion.

\section{Conclusions}

The present work provides a simple heat treatment modification to improve the hydrogen embrittlement resistance of the ultra-high strength Q\&P steels by using the higher partitioning temperature, especially for those hot stamped components that have undergone a Q\&P treatment. By tensile tests of dog-bone samples and notched samples, it is found that the higher partitioning temperature results in smaller elongation loss and von Mises strength reduction. Meanwhile, as the partitioning temperature increases, the hydrogen-assisted fracture morphology changes from 
intergranular to transgranular fracture, consistent with the improved hydrogen embrittlement resistance. The influences of hydrogen, retained austenite, and martensite are discussed. It is found that the hydrogen diffusivity and solubility cannot account for the difference of hydrogen embrittlement. Instead, the less stable retained austenite and the tougher martensite matrix are the major reasons for the improvement of hydrogen embrittlement resistance. Finally, two directions have been proposed for future development of the Q\&P steels with high hydrogen embrittlement resistance, i.e., to improve the intrinsic toughness by reducing the flow stress of martensite matrix and to reduce the hydrogen degradation by tailoring the austenite stability and hydrogen sensitivity of the martensite matrix.

Author Contributions: Conceptualization: Z.W. and M.H.; methodology: Z.W.; validation: Z.W. and M.H.; formal analysis: Z.W.; investigation: Z.W.; resources: M.H.; data curation: Z.W.; writing-original draft preparation: Z.W.; writing—review and editing: M.H.; visualization: Z.W.; supervision: M.H.; project administration: M.H.; funding acquisition: M.H. All authors have read and agreed to the published version of the manuscript.

Funding: This research receives funding from National Natural Science Foundation of China (No. U1764252), National Key Research and Development Program of China (No. 2019YFA0209900, 2017YFB0304401), Research Grants Council of Hong Kong (No. R7066-18, 17255016, 17210418), and Guangzhou Municipal Science and Technology Project (No. 201807010079).

Acknowledgments: Rendong Liu from Ansteel is acknowledged for providing the cold rolled Q\&P steel.

Conflicts of Interest: The authors declare no conflict of interest.

\section{References}

1. Wang, L.; Speer, J.G. Quenching and Partitioning Steel Heat Treatment. Metallogr. Microstruct. Anal. 2013, 2, 268-281. [CrossRef]

2. Huang, M.X.; Liang, Z.Y.; Luo, Z.C. Critical Assessment 15: Science of deformation and failure mechanisms in twinning induced plasticity steels. Mater. Sci. Technol. 2015, 31, 1265-1270. [CrossRef]

3. Yi, H.L.; Sun, L.; Xiong, X.C. Challenges in the formability of the next generation of automotive steel sheets. Mater. Sci. Technol. 2018, 34, 1112-1117. [CrossRef]

4. Speer, J.; Matlock, D.K.; De Cooman, B.C.; Schroth, J.G. Carbon partitioning into austenite after martensite transformation. Acta Mater. 2003, 51, 2611-2622. [CrossRef]

5. Speer, J.G.; Edmonds, D.V.; Rizzo, F.C.; Matlock, D.K. Partitioning of carbon from supersaturated plates of ferrite, with application to steel processing and fundamentals of the bainite transformation. Curr. Opin. Solid State Mater. Sci. 2004, 8, 219-237. [CrossRef]

6. Pierce, D.T.; Coughlin, D.R.; Clarke, K.D.; De Moor, E.; Poplawsky, J.; Williamson, D.L.; Mazumder, B.; Speer, J.G.; Hood, A.; Clarke, A.J. Microstructural evolution during quenching and partitioning of 0.2C-1.5Mn-1.3Si steels with Cr or Ni additions. Acta Mater. 2018, 151, 454-469. [CrossRef]

7. Liu, L.; He, B.B.; Cheng, G.J.; Yen, H.W.; Huang, M.X. Optimum properties of quenching and partitioning steels achieved by balancing fraction and stability of retained austenite. Scr. Mater. 2018, 150, 1-6. [CrossRef]

8. He, B.B.; Liu, L.; Huang, M.X. Room-Temperature Quenching and Partitioning Steel. Metall. Mater. Trans. A Phys. Metall. Mater. Sci. 2018, 49, 3167-3172. [CrossRef]

9. Xiong, Z.; Jacques, P.J.; Perlade, A.; Pardoen, T. Ductile and intergranular brittle fracture in a two-step quenching and partitioning steel. Scr. Mater. 2018, 157, 6-9. [CrossRef]

10. Xiong, Z.; Jacques, P.J.; Perlade, A.; Pardoen, T. Characterization and Control of the Compromise between Tensile Properties and Fracture Toughness in a Quenched and Partitioned Steel. Metall. Mater. Trans. A Phys. Metall. Mater. Sci. 2019, 50, 3502-3513. [CrossRef]

11. Wang, Z.; Huang, M.X. The Role of Retained Austenite Stability on Low-Temperature Mechanical Behaviors of a Quenching and Partitioning Steel. Metall. Mater. Trans. A Phys. Metall. Mater. Sci. 2019, 50, 5650-5655. [CrossRef]

12. Wang, Z.; Huang, M.X. Optimising the strength-ductility-toughness combination in ultra-high strength quenching and partitioning steels by tailoring martensite matrix and retained austenite. Int. J. Plast. 2020, 134, 102851. [CrossRef]

13. Mehner, T.; Scharf, I.; Frint, P.; Schubert, F.; Mašek, B.; Wagner, M.F.-X.; Lampke, T. Hydrogen embrittlement of a quenching and partitioning steel during corrosion and zinc electroplating. Mater. Sci. Eng. A 2019, 744, 247-254. [CrossRef] 
14. Wang, Z.; Luo, Z.C.; Huang, M.X. Revealing hydrogen-induced delayed fracture in ferrite-containing quenching and partitioning steels. Materialia 2018, 4, 260-267. [CrossRef]

15. Yang, J.; Song, Y.; Lu, Y.; Gu, J.; Guo, Z. Effect of ferrite on the hydrogen embrittlement in quenched-partitioned-tempered low carbon steel. Mater. Sci. Eng. A 2017, 712, 630-636. [CrossRef]

16. Nagumo, M. Fundamentals of Hydrogen Embrittlement; Springer: Berlin/Heidelberg, Germany, 2016; pp. 1-239. [CrossRef]

17. Zhu, X.; Zhang, K.; Li, W.; Jin, X. Effect of retained austenite stability and morphology on the hydrogen embrittlement susceptibility in quenching and partitioning treated steels. Mater. Sci. Eng. A 2016, 658, 400-408. [CrossRef]

18. Zhu, X.; Li, W.; Hsu, T.Y.; Zhou, S.; Wang, L.; Jin, X. Improved resistance to hydrogen embrittlement in a high-strength steel by quenching-partitioning-tempering treatment. Scr. Mater. 2015, 97, 21-24. [CrossRef]

19. Ryu, J.H.; Chun, Y.S.; Lee, C.S.; Bhadeshia, H.K.D.H.; Suh, D.W. Effect of deformation on hydrogen trapping and effusion in TRIP-assisted steel. Acta Mater. 2012, 60, 4085-4092. [CrossRef]

20. Zhu, X.; Li, W.; Zhao, H.; Jin, X. Effects of cryogenic and tempered treatment on the hydrogen embrittlement susceptibility of TRIP-780 steels. Int. J. Hydrogen Energy 2013, 38, 10694-10703. [CrossRef]

21. Hu, X.H.; Sun, X.; Hector, L.G.; Ren, Y. Individual phase constitutive properties of a TRIP-assisted QP980 steel from a combined synchrotron X-ray diffraction and crystal plasticity approach. Acta Mater. 2017, 132, 230-244. [CrossRef]

22. Hou, Z.R.; Opitz, T.; Xiong, X.C.; Zhao, X.M.; Yi, H.L. Bake-partitioning in a press-hardening steel. Scr. Mater. 2019, 162, 492-496. [CrossRef]

23. Liu, H.; Lu, X.; Jin, X.; Dong, H.; Shi, J. Enhanced mechanical properties of a hot stamped advanced high-strength steel treated by quenching and partitioning process. Scr. Mater. 2011, 64, 749-752. [CrossRef]

24. Wojdyr, M. Fityk: A general-purpose peak fitting program. J. Appl. Crystallogr. 2010, 43, 1126-1128. [CrossRef]

25. Toby, B.H. EXPGUI, a graphical user interface for GSAS. J. Appl. Crystallogr. 2001, 34, 210-213. [CrossRef]

26. Ungár, T.; Dragomir, I.; Révész, Á.; Borbély, A. The contrast factors of dislocations in cubic crystals: The dislocation model of strain anisotropy in practice. J. Appl. Crystallogr. 1999, 32, 992-1002. [CrossRef]

27. Ungár, T.; Borbély, A. The effect of dislocation contrast on X-ray line broadening: A new approach to line profile analysis. Appl. Phys. Lett. 1996, 69, 3173-3175. [CrossRef]

28. Wang, M.; Huang, M.X. Abnormal trip effect on the work hardening behavior of a quenching and partitioning steel at high strain rate. Acta Mater. 2020, 188, 551-559. [CrossRef]

29. Warren, B.E.; Averbach, B.L. The effect of cold-work distortion on X-ray patterns. J. Appl. Phys. 1950, 21, 595-599. [CrossRef]

30. ASTM. Standard Practice for X-ray Determination of Retained Austenite in Steel with Near Random Crystallographic Orientatio; ASTM: West Conshohocken, PA, USA, 2009; Volume 3, pp. 1-7. [CrossRef]

31. Miyamoto, G.; Oh, J.C.; Hono, K.; Furuhara, T.; Maki, T. Effect of partitioning of Mn and Si on the growth kinetics of cementite in tempered Fe-0.6 mass\% C martensite. Acta Mater. 2007, 55, 5027-5038. [CrossRef]

32. He, B.B.; Huang, M.X.; Ngan, A.H.W.; van der Zwaag, S. Effect of Free Surface on the Stability of Individual Retained Austenite Grains in a Duplex Stainless Steel. Metall. Mater. Trans. A 2014, 45, 4875-4881. [CrossRef]

33. Tirumalasetty, G.K.; Van Huis, M.A.; Kwakernaak, C.; Sietsma, J.; Sloof, W.G.; Zandbergen, H.W. Deformation-induced austenite grain rotation and transformation in TRIP-assisted steel. Acta Mater. 2012, 60, 1311-1321. [CrossRef]

34. Verlinden, B.; Bocher, P.; Girault, E.; Aernoudt, E. Austenite texture and bainite/austenite orientation relationships in TRIP steel. Scr. Mater. 2001, 45, 909-916. [CrossRef]

35. Yuan, L.; Ponge, D.; Wittig, J.; Choi, P.; Jiménez, J.A.; Raabe, D. Nanoscale austenite reversion through partitioning, segregation and kinetic freezing: Example of a ductile $2 \mathrm{GPa} F-\mathrm{Cr}-\mathrm{C}$ steel. Acta Mater. 2012, 60, 2790-2804. [CrossRef]

36. Bouaziz, O.; Zurob, H.; Huang, M. Driving Force and Logic of Development of Advanced High Strength Steels for Automotive Applications. Steel Res. Int. 2013, 84, 937-947. [CrossRef]

37. Koyama, M.; Tasan, C.C.; Akiyama, E.; Tsuzaki, K.; Raabe, D. Hydrogen-assisted decohesion and localized plasticity in dual-phase steel. Acta Mater. 2014, 70, 174-187. [CrossRef] 
38. Fan, Y.H.; Zhang, B.; Yi, H.L.; Hao, G.S.; Sun, Y.Y.; Wang, J.Q.; Han, E.-H.; Ke, W. The role of reversed austenite in hydrogen embrittlement fracture of $S 41500$ martensitic stainless steel. Acta Mater. 2017, 139, 188-195. [CrossRef]

39. Yoo, J.; Jo, M.C.; Kim, D.W.; Song, H.; Koo, M.; Sohn, S.S.; Lee, S. Effects of Cu addition on resistance to hydrogen embrittlement in 1 GPa-grade duplex lightweight steels. Acta Mater. 2020, 196, 370-383. [CrossRef]

40. Sojka, J.; Vodárek, V.; Schindler, I.; Ly, C.; Jérôme, M.; Váňová, P.; Ruscassier, N.; Wenglorzová, A. Effect of hydrogen on the properties and fracture characteristics of TRIP 800 steels. Corros. Sci. 2011, 53, 2575-2581. [CrossRef]

41. Louthan, M.R. Hydrogen embrittlement of metals: A primer for the failure analyst. J. Fail. Anal. Prev. 2008, 8, 289-307. [CrossRef]

42. Hidalgo, J.; Celada-Casero, C.; Santofimia, M.J. Fracture mechanisms and microstructure in a medium Mn quenching and partitioning steel exhibiting macrosegregation. Mater. Sci. Eng. A 2019, 754, 766-777. [CrossRef]

43. Turk, A.; Joshi, G.R.; Gintalas, M.; Callisti, M.; Rivera-Díaz-del-Castillo, P.E.J.; Galindo-Nava, E.I. Quantification of hydrogen trapping in multiphase steels: Part I-Point traps in martensite. Acta Mater. 2020, 194, 118-133. [CrossRef]

44. Turk, A.; Pu, S.D.; Bombač, D.; Rivera-Díaz-del-Castillo, P.E.J.; Galindo-Nava, E.I. Quantification of hydrogen trapping in multiphase steels: Part II-Effect of austenite morphology. Acta Mater. 2020, 197, 253-268. [CrossRef]

45. Pérez Escobar, D.; Depover, T.; Duprez, L.; Verbeken, K.; Verhaege, M. Combined thermal desorption spectroscopy, differential scanning calorimetry, scanning electron microscopy and X-ray diffraction study of hydrogen trapping in cold deformed TRIP steel. Acta Mater. 2012, 60, 2593-2605. [CrossRef]

46. Jacques, P.; Furnémont, Q.; Pardoen, T.; Delannay, F. On the role of martensitic transformation on damage and cracking resistance in TRIP-assisted multiphase steels. Acta Mater. 2001, 49, 139-152. [CrossRef]

47. Lacroix, G.; Pardoen, T.; Jacques, P.J. The fracture toughness of TRIP-assisted multiphase steels. Acta Mater. 2008, 56, 3900-3913. [CrossRef]

48. Bhadeshia, H.K.D.H. Prevention of Hydrogen Embrittlement in Steels. ISIJ Int. 2016, 56, 24-36. [CrossRef]

49. Krauss, G. Tempering of Lath Martensite in Low and Medium Carbon Steels: Assessment and Challenges. Steel Res. Int. 2017, 88, 1-18. [CrossRef]

50. Jiang, F.; Masumura, T.; Hirata, K.; Tsuchiyama, T.; Takaki, S. A new diffraction line profile breadth analysis approach for evaluating plastic lattice strain anisotropy in cold-worked nickel under various strain paths. Int. J. Plast. 2019, 112, 89-107. [CrossRef]

51. Harjo, S.; Kawasaki, T.; Tomota, Y.; Gong, W.; Aizawa, K.; Tichy, G.; Shi, Z.; Ungár, T. Work Hardening, Dislocation Structure, and Load Partitioning in Lath Martensite Determined by In Situ Neutron Diffraction Line Profile Analysis. Metall. Mater. Trans. A Phys. Metall. Mater. Sci. 2017, 48, 4080-4092. [CrossRef]

52. Xiao, L.; Fan, Z.; Jinxiu, Z.; Mingxing, Z.; Mokuang, K.; Zhenqi, G. Lattice-parameter variation with carbon content of martensite. I. X-ray-diffraction experimental study. Phys. Rev. B 1995, 52, 9970-9978. [CrossRef]

53. Geng, W.T.; Wang, V.; Xu, J.; Ishikawa, N. Hydrogen trapping in carbon supersaturated-Iron and its decohesion effect in martensitic steel. Scr. Mater. 2018, 149, 1-15. [CrossRef]

54. Horn, R.M.; Ritchie, R.O. Mechanisms of tempered martensite embrittlement in low alloy steels. Metall. Trans. A 1978, 9, 1039-1053. [CrossRef]

Publisher's Note: MDPI stays neutral with regard to jurisdictional claims in published maps and institutional affiliations.

(C) 2020 by the authors. Licensee MDPI, Basel, Switzerland. This article is an open access article distributed under the terms and conditions of the Creative Commons Attribution (CC BY) license (http://creativecommons.org/licenses/by/4.0/). 